\title{
A perspectiva dos pais de recém-nascidos pré-termo acerca do método canguru
}

\author{
The parents' perspective of low birth weight newborn about the kangaroo method \\ La perspectiva de los padres del recién nacidos con bajo peso sobre el método canguro
}

Recebido: 18/01/2021 | Revisado: 23/01/2021 | Aceito: 26/01/2021 | Publicado: 03/02/2021

\author{
Mayara Carolina Cañedo \\ ORCID: https://orcid.org/0000-0002-7232-1431 \\ Hospital Regional de Mato Grosso do Sul, Brasil \\ E-mail: maycarolina@hotmail.com \\ Cristina Brandt Nunes \\ ORCID: https://orcid.org/0000-0003-2411-0717 \\ Universidade Federal de Mato Grosso do Sul, Brasil \\ E-mail: cbrandtnunes@gmail.com \\ Maria Aparecida Munhoz Gaiva \\ ORCID: https://orcid.org/0000-0002-9699-6417 \\ Universidade Federal de Mato Grosso, Brasil \\ E-mail: mamgaiva@yahoo.com.br \\ Ana Cláudia Garcia Vieira \\ ORCID: https://orcid.org/0000-0003-4982-6148 \\ Universidade Federal de Pelotas, Brasil \\ E-mail: cadicha10@gmail.com \\ Iluska Lopes Schultz \\ ORCID: https://orcid.org/0000-0002-2212-2186 \\ Secretaria Municipal de Saúde de Corumbá, Brasil \\ E-mail: ilulschultz@gmail.com
}

\begin{abstract}
Resumo
Este estudo visa analisar as percepções dos pais de recém-nascidos pré-termo sobre o Método Canguru. Trata-se de uma pesquisa qualitativa, modalidade Estudo de Caso, cujos dados foram obtidos entre março e dezembro de 2016, mediante entrevistas semiestruturadas com 12 mães e três pais de recém-nascidos pré-termo, em um hospital de ensino de Campo Grande - MS, Brasil, sendo suas narrativas submetidas à técnica de análise de conteúdo temática. Os dados coletados foram agrupados em três núcleos temáticos: "O Método Canguru como contribuinte para a aproximação e formação do vínculo entre pais e filho"; "O Método Canguru como favorecedor do crescimento e desenvolvimento do filho pré-termo"; e "O Método Canguru como facilitador do aleitamento materno exclusivo". Na descrição destas percepções, encontraram-se como benefícios do método a construção do vínculo entre pais e filhos, a aceleração do ganho de peso do bebê, melhor desenvolvimento motor, incentivo à amamentação e à alta precoce, coincidindo com as vantagens descritas pela literatura vigente.
\end{abstract}

Palavras-chave: Recém-nascido de baixo peso; Recém-nascido prematuro; Método canguru; Humanização da assistência.

\begin{abstract}
This study aims to analyze the parents perception of Low Birth Weight Newborn about the Kangaroo Method (KM). It's a qualitative research, in Case Study mode, whose data were obtained between March and December 2016, by conducting semi-structured interviews with 12 mothers and three fathers of the Low Birth Weight Newborn, in a university hospital in Campo Grande - MS, Brazil, and their narratives were subjected to thematic content analysis technique. The collected data were grouped into three thematic groups: "The Kangaroo Method as a contributor to the approximation and formation of the bond between parents and child"; "The Kangaroo Method as a growth and development promoter of the premature child preterm"; and "The a Kangaroo Methods a facilitator breastfeeding exclusive". In describing these perceptions, as method benefits were found the bond construction between parents and children, the baby's weight gain acceleration, greater motor development, encouraging breastfeeding and early discharge, coinciding with the advantages described by the current literature.
\end{abstract}

Keywords: Low weight newborn; Premature newborn; Kangaroo method; Humanization of assistance.

\section{Resumen}

Este estudio tiene como objetivo analizar la percepción de los padres del Recién Nacidos con Bajo Peso sobre el Método Canguro. Es una investigación cualitativa, en modo de estudio de caso, cuyos datos se obtuvieron entre marzo y diciembre de 2016, por medio de entrevistas semiestructuradas con 12 madres y tres padres del Recién Nacidos con Bajo Peso, en un hospital docente en Campo Grande - MS, Brasil, y sus narrativas fueron sometidas a la técnica de análisis de contenido temático. La percepción de los padres sobre lo MC experimentado en el contexto hospitalario se 
agrupaba en tres grupos temáticos: "Lo Método Canguro como contribuyente a la aproximación y formación del vínculo entre padres e hijos"; "El Método Canguro como promotor del crecimiento y desarrollo del niño prematuro"; y "El Método Canguro como facilitador de la lactancia materna exclusiva". En la descripción de estas percepciones, los beneficios del método fueron la construcción del vínculo entre padres e hijos, la aceleración del aumento de peso del bebé, mayor desarrollo motor, fomentar la lactancia materna y el alta temprana, coincidiendo con las ventajas descritas en la literatura actual.

Palabras clave: Recién nacido de bajo peso; Recién nacido prematuro; Método canguro; Humanización de la assistência.

\section{Introdução}

A prematuridade é considerada um problema de saúde pública no país e está associada ao baixo peso ao nascer, e é responsável por elevadas taxas de morbimortalidade no período neonatal (Oliveira, et. al., 2016). Frente a essa problemática, no início dos anos 2000, o Ministério da Saúde instituiu o Método Canguru (MC) como uma Política de Saúde brasileira voltada aos recém-nascidos de baixo peso (RNBP) (Ministério da Saúde, 2017). Ao contrário dos outros países, no Brasil o método foi implantado de maneira mais abrangente e engloba o pré-natal das gestantes com risco de parto prematuro, o nascimento, a hospitalização, a alta e as consultas dos RNBP (Ferreira, Monteiro \& Souza, 2020).

A aplicação do MC está dividida em três etapas: a primeira se inicia no pré-natal de alto-risco, no nascimento de um recém-nascido pré-termo (RNPT) e, posteriormente, pela internação da criança na unidade neonatal. A segunda etapa tem início após a estabilização das condições clínicas do bebê, que passará a maior parte do tempo possível em contato pele a pele com seus pais, estimulando-se assim o contato físico e o vínculo. A terceira etapa começa na alta hospitalar do bebê, com o acompanhamento ambulatorial ou domiciliar até que a criança atinja 2.500 gramas, dando continuidade à assistência (Ministério da Saúde, 2017).

A literatura e as experiências dos serviços evidenciam que o MC é uma intervenção viável, que propicia inúmeros benefícios ao RNPT, dentre eles: redução da mortalidade; diminuição de infecções durante a internação; controle da dor; estabilidade cardiorrespiratória; auxílio no desenvolvimento neuropsicomotor do recém-nascido (RN); favorecimento do vínculo entre pais e filhos; a amamentação exclusiva; dentre outros (Costa, et. al., 2015).

Por sua vez, o envolvimento das mães com o MC dependerá de sua concepção de gravidez e parto prematuro, bem como de sua história pessoal e familiar. Assim, no hospital, é necessário criar estratégias para que os pais compreendam que o MC não é apenas a Posição Canguru (PC), mas o quanto é fundamental também para o fortalecimento do vínculo, para a manutenção da amamentação e para a construção da parentalidade, assim como o preparo para a participação dos pais no cuidado dos filhos dentro da Unidade de Terapia Intensiva Neonatal (UTIN) e ao desenvolvimento de competências para o cuidado no ambiente domiciliar (Dantas, et. al., 2018; Souza et. al., 2019).

A realização deste estudo se justifica pela importância de compreender a visão dos pais/familiares sobre o MC, concedendo visibilidade as suas percepções e entendimento sobre como ocorre a sua participação nos procedimentos rotineiros. Sua relevância pauta-se na geração de subsídios para gestores e profissionais de saúde, a fim de potencializar o desenvolvimento dessa estratégia nos hospitais, estimular a participação familiar e, ainda, visando à qualificação da atenção. Em vista disso, a questão de pesquisa foi assim delineada: Qual é a percepção dos pais sobre o MC desenvolvido no ambiente do hospital? Assim, o objetivo da pesquisa consistiu em analisar as percepções dos pais de RNPT acerca do MC realizado no contexto hospitalar.

\section{Metodologia}

Estudo qualitativo, na modalidade Estudo de Caso, desenvolvido em um hospital de ensino de Campo Grande, Mato Grosso do Sul (MS), Brasil. Desde 2012, o hospital encontra-se habilitado como referência estadual para o MC, sendo 
credenciado também como Iniciativa Hospital Amigo da Criança (IHAC).

Os Estudos de Caso mapeiam, descrevem e analisam as relações, os contextos e as percepções sobre uma determinada situação, além de permitir esclarecer os fatores que interferem nos processos e de possibilitar a sua replicação em situações semelhantes (Yin, 2015).

Participaram do estudo pais que tiveram a experiência de ter seus filhos prematuros hospitalizados na unidade neonatal. Os critérios de inclusão foram pais e mães, independente da idade, residentes na capital ou no interior do estado, que participaram de todas as etapas do método. Foram excluídos do estudo mães e pais que a pesquisadora não localizou o endereço para realizar a visita domiciliar. Foi realizado um contato prévio com os pais para convidá-los a participar da pesquisa. Não houve recusa dos pais em participar do estudo. Assim, a investigação contou com a participação de 12 mães e três pais, totalizando 15 participantes. O número de pessoas entrevistadas foi definido a partir do momento em que as informações se mostraram suficientes para responder ao objetivo do estudo.

A coleta de dados ocorreu de março a dezembro de 2016, por meio de entrevista semiestruturada, quando os pais participavam da terceira etapa do método, a qual foi conduzida a partir de um roteiro, contendo dados de identificação e duas questões guias, quais sejam: Em sua opinião, o que é o MC? E como é ter um filho no Cuidado Canguru?

As entrevistas foram realizadas em domicílio ou no consultório na terceira etapa do método, e em horário escolhido pelos participantes, sendo gravadas em áudio e depois transcritas, conservando-se as expressões de linguagem utilizadas pelos mesmos. Todas as entrevistas foram realizadas individualmente, com exceção de uma, cujo casal optou por participar da pesquisa e da entrevista conjuntamente. A média de duração de cada encontro foi de 28 minutos.

Para a análise dos dados, foi utilizada a técnica de análise de conteúdo na modalidade análise temática proposta por (Gomes, 2016), constituída por três etapas interligadas: pré-análise, que consistiu na seleção dos documentos a serem analisados e no resgate dos objetivos do estudo; exploração do material transcrito com leitura em profundidade dos diálogos, que possibilitou captar os núcleos de sentido e classificar os achados em categorias empíricas; e tratamento dos resultados alcançados e interpretação dos dados brutos, os quais foram submetidos às análises. A partir daí, se realizou interpretações, inter-relacionando-as com o referencial teórico da Política Nacional de Atenção Humanizada ao Recém-Nascido - Método Canguru e da literatura científica nacional e internacional sobre o tema.

A pesquisa foi aprovada pelo Comitê de Ética em Pesquisa com Seres Humanos da Universidade Federal de Mato Grosso do Sul, com o protocolo CAAE n ${ }^{\circ}$. 51279715.6.0000.0021, Parecer n. ${ }^{\circ}$ 1.371.216 aprovado em 16/12/2015, seguindo todos os preceitos éticos previstos nas Resoluções 466/2012 - 510/2016 - 580/2018, do Ministério da Saúde. Os participantes do estudo leram e assinaram o Termo de Consentimento Livre e Esclarecido (TCLE). Os pais e os responsáveis pelas mães adolescentes foram informados sobre a pesquisa, e os que concordaram com a participação, assinaram o TCLE, sendo que as adolescentes assinaram o Termo de Assentimento Livre e Esclarecido. Para preservar a identidade dos participantes, os relatos foram identificados como mãe ou pai e o número da entrevista subsequente (Mãe 1, Pai 1).

\section{Resultados e Discussão}

As percepções dos pais sobre o MC experienciadas no ambiente hospitalar foram agrupadas em três núcleos temáticos: "O MC como contribuinte para a aproximação e formação do vínculo entre pais e filho"; "O MC como favorecedor do crescimento e desenvolvimento do filho pré-termo"; e "O MC como facilitador do aleitamento materno exclusivo".

\section{O MC como contribuinte para a aproximação e formação de vínculo entre pais e filho}

O MC é um novo paradigma na assistência ao prematuro e, para tal, a entrada e permanência dos pais na unidade neonatal deve ser estimulada. Para os pais entrevistados, o MC significa um cuidado que permite a aproximação deles com os 
filhos, conforme demostram as falas a seguir:

A doutora falou que o Método Canguru é pra você ficar mais com seus filhos amarrados, para eles estarem mais próximos de você (MÃE 1).

[...] Sem contar que eles ficam bem mais próximos da gente, a gente vai criando mais amor por eles (MÃE 2).

\section{[...] Que era melhor pra eles e para o vínculo com a mãe (MÃE 3).}

A pesquisa realizada em unidade neonatal de um hospital-escola no Sul do Brasil, com a participação de nove mães vivenciando o MC, revelou que, em suas percepções, a PC proporciona sentimentos de emoção e alegria por transmitir carinho e calor aos filhos, além de criar condições para o fortalecimento e estabelecimento do vínculo e do apego (Heck, et. al., 2016).

Esta percepção também foi evidenciada por enfermeiras atuantes na unidade materno-infantil de um hospital universitário, do interior de Minas Gerais, Brasil, que descreveram como potencialidades do MC a criação de vínculo e a construção de laços afetivos entre o neonato e a mãe, estendendo-se à promoção de vínculo junto ao pai, familiares ou outras pessoas próximas ao RN (Ferreira, et. al., 2019).

As mães entrevistadas relacionam o contato pele a pele como uma continuação da gestação, que foi interrompida pelo parto prematuro:

Até a posição é como se elas estivessem na barriga ainda, acho que eles devem se sentir assim. Então, eu acho que isso ajuda. Pra mim, é isso, é essa posição pele a pele, contato com a mãe. O meu marido também falou que parecia que ela estava na barriga dele, como se ele estivesse grávido (risos) dela [...] (MÃE 11).

Eu ficava bastante tempo com ele no colo, pra ele se sentir mais protegido. Por ele ser prematuro, ele acha que ainda tá [sic] dentro da barriga (MÃE 2).

O MC é também uma forma de acolher a família e, em especial, a mãe, que vivencia de modo peculiar os impactos causados pelo parto antecipado. Assim, a mãe deve ter a oportunidade de se aproximar da rotina de cuidados do filho, durante a hospitalização:

[...] A gente vai conhecendo eles, cada dia que passa, porque a gente tá [sic] cuidando, a gente tá [sic] perto, tá [sic] do lado um do outro (MÃE 2).

Eu acho assim, que o Método Canguru foi mais para minha aproximação com ele, para aprender a cuidar dele, para ter mais um vínculo entre mãe e filho [...] (MÃE 3).

A participação da família é fundamental para o desenvolvimento do MC. É necessário que a mãe tenha amor, confiança e disponibilidade de tempo para se dedicar ao filho. Ao executar os cuidados, os pais sentem que assumem o seu papel, visto que, por um determinado período, seu filho pertenceu à equipe e, ao cuidarem dele, resgatam a sua função e se percebem mais preparados para a alta da unidade neonatal (Aires, et. al., 2020).

No entanto, quando se delegam alguns cuidados da criança aos pais, não significa desresponsabilizar o profissional de enfermagem, pois este deverá supervisionar, identificar dificuldades, compartilhar os cuidados e fornecer as orientações necessárias. A equipe de enfermagem deve estimular o encontro entre os pais e os neonatos, além de proporcionar o compartilhamento de cuidados, de modo que os pais não se sintam assoberbados, mas consigam compreender e desempenhar seu papel junto ao filho (Souza, et. al., 2019).

O pai relata a sua experiência ao visitar a filha na UTIN: 
Eu ficava com ela, eu conversava com ela desde que estava lá dentro daquela estufa, ela começava a se mexer, aí você pegava nela, ela ficava quietinha [...] (PAI 3).

O pai ressalta que, quando a filha iniciou a PC, melhorou seu vínculo com o bebê:

E a facilidade se tornou quando nós conhecemos o Método Canguru. Ficou muito mais fácil para nós. Nossa, muda da água para o vinho com o Método Canguru! Você fica mais próximo da sua filha, ela sente mais você. É pele com pele, como já é o método (PAI 2).

Os pais enfrentam todas as dificuldades para estar por mais tempo ao lado do filho hospitalizado e é importante que se reconheçam como pais. Nesse sentido, a equipe de enfermagem deve ajudar nessa aproximação do pai com o filho pré-termo, na perspectiva de equidade de gênero (Lopes, et. al., 2019).

O MC pode ser considerado como facilitador no processo de formação de vínculo mãe-pai-bebê, já que proporciona a inserção e participação mais direta do pai no cuidado ao filho, além da aproximação da família como um todo:

Ele une mais o casal. Ele uniu bastante eu, minhas filhas e o meu marido (MÃE 8).

No discurso a seguir, o pai relata que optou por acompanhar as filhas prematuras e a esposa durante este período de hospitalização:

Eu larguei o emprego para vir ficar com elas no hospital. A enfermeira falou que o Canguru as ajuda no desenvolvimento, no peso e também ajuda a ter convivência. Que sempre é para estarmos com elas próximas no corpo a corpo [...]. Em minha opinião, o Método Canguru ajudou a gente, como elas nasceram com 600 e 900 gramas, elas não teriam chance de vida, se não fosse o Método Canguru [...] (PAI 1).

A fragilidade do RNPT e o desejo de estar ao seu lado faz com que os pais optem pelo MC, dando prioridade a esse filho hospitalizado, deixando de lado as demais necessidades familiares. Esta atitude acarreta alterações no cotidiano da família, portanto, demandando o apoio dos membros da equipe de saúde. A formação do vínculo mãe-pai-bebê ocorre de maneira gradativa (Souza, et. al., 2019), e quanto mais oportunidades forem oferecidas, maior será a probabilidade de resposta afetiva (Ferreira, et. al., 2019).

\section{O MC como favorecedor do crescimento e desenvolvimento do filho pré-termo}

Para os pais participantes do estudo, o MC traz diversos benefícios para os filhos nascidos prematuros, dentre eles, o ganho de peso, o estímulo ao desenvolvimento, a alta precoce e a segurança dos pais para a realização dos cuidados. Além desses aspectos, segundo eles, os bebês ficam mais calmos e dormem melhor. Nas falas a seguir, se percebe a ênfase dada pelos pais ao ganho de peso do pré-termo:

O Canguru, assim, o que a gente leva e fica com a criança todo o tempo, ela ganha peso, é um processo mãe e filho muito grudado (MÃE 10).

É ficar com a criança no colo para ela ganhar mais peso (MÃE 5).

[...] Eu falava assim: ai, eu acho que vou ganhar a mãe canguru do ano, porque o tanto que eu fazia e o tanto de peso que ela sobressaía com relação às outras crianças! Eu acho que, comprovadamente, a criança que fica no método pele a pele ganha mais peso (MÃE 4). 
[...] A técnica de enfermagem de lá explicou que ajuda o bebê a ganhar peso, que é por isso que as mães que vão lá para o Canguru, tentam ficar o maior tempo possível com os bebês, desse jeito (MÃE 11).

Estudo transversal realizado no estado de Rondônia, Brasil, com 86 RNPT, dividido em dois grupos: um com 48 prétermos submetidos ao contato pele a pele (por $8 \mathrm{~h} /$ dia, pelo menos); e outro com 38 prematuros não submetidos ao contato pele a pele evidenciou que a PC influencia positivamente no ganho de peso e no tempo de internação dos neonatos (Souza, et. al., 2018).

A preocupação dos pais com o ganho de peso dos filhos nascidos prematuros se justifica já que um dos critérios utilizados para a alta hospitalar desses RN é o ganho de peso diário por três dias consecutivos, sendo que o peso mínimo exigido é de 1.600 gramas (Ministério da Saúde, 2017).

Para uma das mães, a PC favorece o ganho de peso e facilita a eructação após a amamentação: O Método Canguru, que é o do peitinho de colocar ele em pezinho aqui, é importante pra criança, pra fazer arrotar, pra fazer engordar, para eles terem contato com a mãe, que é o que fez muito bem para os meus filhos, que eu acho que engordou muito eles fazendo o Método Canguru (MÃE 9).

A PC mantém a oxigenação adequada, estabiliza a frequência respiratória, evita episódios de apneia, refluxo e broncoaspiração (Costa, et. al., 2015). Após as mamadas, se orienta que as crianças sejam mantidas em contato pele a pele, pois o RNPT regurgita com facilidade.

O MC é percebido pelos participantes da pesquisa como uma estratégia importante para o crescimento e desenvolvimento do bebê pré-termo:

O RNPT tem seu crescimento e desenvolvimento intrauterino suspenso pelo parto antecipado e esses prejuízos podem se prolongar nos primeiros anos de vida da criança. O estudo realizado com prontuários de crianças nascidas pré-termo e com muito baixo peso, acompanhadas no ambulatório de um hospital no oeste do Paraná, mostrou que nascer pequeno para a idade gestacional (PIG) causou prejuízo no crescimento nos primeiros 12 meses de vida (Rover, et. al., 2016). Por sua vez, um estudo de revisão sistemática e metanálise concluiu que uma em cada seis crianças nascidas pré-termo ou com muito baixo peso apresenta atraso em seu desenvolvimento cognitivo e motor, nas avaliações realizadas até os dois anos de idade corrigida (Pascal, et. al., 2018).

Nesse sentido, o Ministério da Saúde recomenda que essas crianças tenham seu crescimento e desenvolvimento acompanhados, ambulatorialmente, após a alta hospitalar e avaliados de acordo com a idade gestacional corrigida até os dois anos de vida (Ministério da Saúde, 2017).

Os benefícios da PC no processo de crescimento e desenvolvimento do pré-termo já foram observados em outras pesquisas, tal como em uma revisão de literatura, na qual evidenciou ser mais favorável com relação ao desenvolvimento neuromotor precoce e também quanto às taxas de crescimento significativamente maiores, como o ganho de peso, aumento da circunferência da cabeça e da circunferência do braço (Zirpoli, et. al., 2019). A PC mesmo quando realizada por um curto período contribui para o ajuste postural e para o desenvolvimento motor do RNPT (Diniz, et. al., 2020).

Outro aspecto do desenvolvimento destacado pelos pais foi o efeito da PC no comportamento dos bebês, acalmandoos:

E eles ficam mais calmos, mais sossegados; esquece aqui; parece que dormem mais tranquilos [...] (MÃE 7).

O Método Canguru acalma a criança, ajuda a criança a engordar. Eu tive essa experiência, eu fiz com as minhas filhas e, pra mim, foi uma experiência muito boa e eu aconselho a passar adiante [...] ajuda a desestressar, quando a criança estiver estressada, o Método Canguru, acalma, fica tranquila [...] (PAI 2). 
E vai se desenvolvendo bem mais e vai ganhando peso, sem contar que eles ficam tão quietinhos, quando tá [sic] colado na gente (MÃE 2).

O MC é uma intervenção natural, eficaz e de baixo custo que promove inúmeros benefícios para o RNPT, saudáveis ou doentes, como nos aspectos fisiológicos, comportamentais e analgésicos, além de suscitar menos estresse e de autoeficácia melhorada nos pais (Ministério da Saúde, 2017). Ademais, a PC materna é considerada uma estratégia para a promoção do sono do RN (Correia \& Lourenço, 2020).

Como relatado na fala do Pai 2, os benefícios da PC paterna assemelham-se à PC materna, contudo, a pouca ajuda e estímulo por parte dos profissionais, a falta de oportunidades e as questões de gênero dificultam a sua prática. A prática do MC é de suma importância para o desenvolvimento do bebê, independentemente de ser implementada pela mãe ou pelo pai (Lopes, et. al., 2019). No entanto, há uma ausência das discussões de gênero na literatura e a reafirmação do lugar de coadjuvante do pai como cuidador.

No hospital de ensino em que este estudo foi realizado, as mães são as acompanhantes dos filhos, mas os pais podem fazer a PC, se desejarem. Na situação de gemelares, as avós, os pais ou outro familiar, de preferência da mãe, podem acompanhar a puérpera e as crianças. Assim, a mãe acompanha um bebê e o pai ou outro familiar, outro bebê. Essa prática foi destacada na fala da Mãe 11:

Colocaram uma em mim e uma no pai, e aí, foi bom! Foi tão bom que nós dormimos, dormiu todo mundo (risos): as bebês, eu e ele! Foi isso, foi muito bom (MÃE 11).

As mães também perceberam que o contato pele a pele proporcionava melhora clínica precoce do filho pré-termo: $A$ recuperação é rápida (MÃE 7).

Eu acho que é uma forma de ajudar o bebê a evoluir mais rápido, sair de lá mais rápido[...] (MÃE 11).

Estudos internacionais, assim como as pesquisas nacionais, demonstram que o engajamento dos pais no $\mathrm{MC}$ com o suporte dos profissionais de saúde promove melhora nos resultados clínicos, com diminuição de complicações associadas a infecções e menor tempo de permanência do pré-termo internado na UTIN, bem como proporcionam maior confiança e satisfação dos pais, aumento no vínculo materno e nas taxas de amamentação (Ministério da Saúde, 2017). Pesquisa desenvolvida na Coreia do Sul, com 45 bebês pré-termos, evidenciou que o MC é seguro para essas crianças, além de diminuir a ansiedade materna, aumentar o apego entre mãe e filho e reduzir o tempo de hospitalização (Lim, et. al., 2015).

No entanto, a implementação desse método ainda não é realidade na maioria das maternidades do nosso país, pois a sua institucionalização só ocorreu a partir dos anos 2000 e muitas mulheres/mães desconhecem a estratégia, como pode ser observado na fala da Mãe 6: Na verdade, eu nem sabia o que era Método Canguru até eu ir para lá. Em estudo realizado com 11 mães que acompanhavam seus filhos na UCINCa, em uma maternidade-escola da cidade do Rio de Janeiro - RJ, Brasil, esse desconhecimento também foi observado, pois a maioria $(81,82 \%)$ só conheceu o método quando foi convidada a participar do Alojamento Canguru (Dantas, et. al., 2018).

Diante desse cenário, a implementação do MC nas maternidades, se revela necessário e ético, ao mesmo tempo em que representa um desafio à equipe de saúde, no sentido de atender às demandas singulares de cuidados e preparar os pais para essa tarefa, gradativamente, além de lhes auxiliar a lidar com a fragilidade e o estresse de ter um filho RNPT.

\section{O MC como facilitador do aleitamento materno exclusivo}

Para algumas mães, a aplicação do MC traz diversos benefícios ao filho pré-termo, dentre eles, auxiliá-las e prepará- 
las para a amamentação:

É bom para ensinar a gente a amamentar melhor, direito, da forma correta, pra você ter mais proximidade com seu bebê, que é o de por no Canguru, ali, senti [sic] ele, você tem que sentir. É bom, que daí, você amamenta bem, que eles te ensinam uma posição que você sente seu bebê melhor, que você o sente amamentar. Não mexe com algumas coisas, atenção só para seu bebê, aquela hora de amamentar, só você e seu bebê (MÃE 6).

A realização do contato pele a pele, após o nascimento, favorece as tentativas de contato físico do filho com a mãe e a maior disponibilidade do RN durante a amamentação. Dessa forma, o contato pele a pele é considerado um estímulo ao aleitamento materno exclusivo (AME), por possibilitar uma maior frequência, periodicidade e duração da amamentação, conforme relata a Mãe 9:

[...] Eu vi que, a partir daí, eles começaram a se desenvolver mais, tanto é que as enfermeiras falavam: faz Canguru, faz Canguru. Eu fazia. O peso, no final do dia, pulava. Aí, eu via que fazia muito bem, sentia. O seio chegava a dar aquelas, umas pontadas assim, ele sente que a criança tá [sic] ali, e eu creio que a criança também sente muito isso da mãe, assim. Aí, fez muito bem para eles, eu achei (MÃE 9).

Estudo evidenciou como uma das vantagens da PC o estímulo à descida do leite, devido ao fortalecimento do vínculo entre mãe e filho, e pela proximidade com o seio materno, que faz com que o bebê desenvolva o reflexo de busca e, consequentemente, o estímulo ao aleitamento materno (AM) (Costa, et. al., 2015).

$\mathrm{O}$ ato de amamentar precocemente as crianças de baixo peso é percebido pelas participantes do estudo como um importante fator para o aumento do vínculo entre mãe e filho e o AM: [...] Então, pra mim, foi muito interessante, foi muito bom o que eu passei ali, o aprendizado que eu tive com elas, ainda mais que são duas, ensinar as duas a mamar ao mesmo tempo, as fono ali acompanhando [...] (MÃE 12).

Uma pesquisa desenvolvida na cidade de Maceió, Alagoas, Brasil, com 30 RNPT participantes do MC e 30 não participantes, mostrou que os bebês que fizeram a PC apresentaram melhor vínculo com as mães e com a prática do AM, tornando-se, para as mães, algo concreto e prático (Melo, et. al., 2016).

Por sua vez, um estudo retrospectivo realizado com dados de prontuários de RN internados na UTIN, de um hospital de ensino de Sumaré, São Paulo, demonstrou que a PC foi associada ao maior oferecimento de leite em livre demanda na amostra de RNPT, mas não houve associação com o AME (Farias, et. al., 2017).

Na fala da Mãe 10, se observa o reconhecimento do papel fundamental dos profissionais de saúde para o sucesso da prática do AM no MC: [...] Eu achei que foi muito importante os profissionais porque, se fosse antes, a primeira coisa seria eu desistir: deixa o peito pra lá e vamos dar só complemento, senão essa criança vai emagrecer [...].

O AME é um desafio para os profissionais que atuam na unidade neonatal, em função das especificidades do RNPT. Nesse sentido, as condutas e as rotinas hospitalares podem facilitar essa prática, como a PC, que gera mais confiança à mãe para amamentar, além de estimular o elo entre mãe e filho (Sales, et al., 2018).

A mãe que usou a PC com as filhas gêmeas, expressa como foi o seu processo de lactação e sua satisfação em conseguir amamentar as filhas nascidas prematuras:

[...] Primeiro eu achava que não tinha leite. Daí, quando colocou uma, estava até de boa, mas quando colocou as duas [...] Foi uma experiência bem grande. E os outros perguntam: como é amamentar dois nenéns? É diferente! Para uma pessoa que nunca amamentou, é bom. Eu fico feliz quando ponho as minhas filhas para mamar as duas juntas. Fico muito feliz! Daí, me aproximo mais das duas, e elas se aproximam mais de mim, ao mesmo tempo [...] (MÃE 8).

O processo de amamentação do RNPT, sobretudo, dos gemelares, além de ser um grande desafio para as mães, exige 
maior atenção e apoio dos profissionais da unidade neonatal, incluindo a atuação fonoaudiológica. Um estudo documental retrospectivo de dados de prontuários dos RN internados em um hospital escola, da cidade de São José do Rio Preto - São Paulo, Brasil, concluiu que a estimulação fonoaudiológica, adaptada ao modelo proposto pelo MC, ou seja, que os bebês sejam colocados precocemente em seio materno, melhora o prognóstico do aleitamento, favorecendo a retirada antecipada de via alternativa de alimentação e a alta fonoaudiológica, viabilizando a via oral exclusiva e o ganho de peso do RN (Basso, et. al., 2018).

$\mathrm{Na}$ impossibilidade de amamentar o filho no seio materno devido a sua instabilidade clínica, os profissionais de enfermagem podem estimular a participação dos pais na administração da dieta por gavagem, a fim de que eles se sintam participantes da alimentação do filho. Situação essa observada neste estudo, por meio da fala do pai 2 , ao destacar que o método auxilia na administração da dieta por sonda:

Até pra passar a dieta, a minha nenê estava na sonda e, fora do Canguru, ela chorava, o leite voltava. Quando eu a colocava no Canguru, ela acalmava, tanto que pra fazer a dieta dela, o Método Canguru é bom. O Método Canguru não é bom só pra ganhar peso, essas coisas só não. Ele é bom para muitas outras funções, que a gente talvez nem conheça ainda (PAI 2).

O MC apresenta muitas vantagens e benefícios concernentes ao AM, sendo alguns deles destacados pelos participantes da presente pesquisa e reafirmados pela literatura, dentre eles: a melhora do prognóstico do aleitamento materno entre os pré-termos; a retirada precoce de via alternativa de alimentação (enteral ou oral) (Basso, et. al., 2018); o maior oferecimento de leite materno em livre demanda (Farias, et. al., 2017) e o aumento da sobrevida desses RN (Sales, et al., 2018).

Revisão integrativa cujo objetivo era pesquisar a influência do MC sobre o AM de pré-termos evidenciou que em todos os 21 estudos selecionados, havia prevalência de AM exclusivo e misto, no momento da alta dos bebês hospitalizados no alojamento canguru quando comparados aos bebês que saiam de alta das unidades convencionais (Alves, et. al., 2020). Outra revisão integrativa que objetivou identificar as atribuições do enfermeiro diante dos cuidados atribuídos no MC revelou a importância deste profissional no gerenciamento da unidade, no acolhimento, nas orientações, na PC e na promoção do AM exclusivo (Brito, et al., 2020).

As orientações sobre o MC realizadas pelos profissionais às famílias devem ser constantes, visando lembrar os benefícios do contato pele a pele para o RN, a importância dos cuidados com base no MC e a importância do AME, além de estabelecer estratégias para solucionar as dificuldades encontradas diariamente tanto pelos pais como pelos profissionais (Nietsche, et. al., 2020).

Como uma limitação do estudo se destaca a pequena participação de pais, comparada ao número de mães. Todavia, se considera que os resultados são relevantes, já que o hospital estudado foi o primeiro no estado de Mato Grosso do Sul a ser habilitado para o MC e a IHAC. Assim, os achados poderão subsidiar gestores e profissionais de saúde a implementarem mudanças e melhor qualificar a atenção prestada.

\section{Considerações Finais}

Para os pais de RNPT o MC contribui para a aproximação e formação do vínculo entre pais e filhos, favorece o crescimento e desenvolvimento do pré-termo e também facilita o AME. Os achados da pesquisa contribuem para a compreensão mais aprofundada sobre como o MC vem sendo experienciado e percebido pelos pais, o que possibilita ampliar o conhecimento em relação à humanização da atenção ao neonato pré-termo. Ainda, promove o entendimento de certos aspectos importantes da participação do pai (gênero masculino) na PC e de fatores sociais que também precisam ser melhor explorados 
em pesquisas sobre a aplicação do método.

Os resultados deste estudo podem contribuir com a prática profissional tendo em vista a importância da participação dos pais em todas as etapas do MC, em especial no momento do nascimento e hospitalização, momento em que os pais se encontram mais fragilizados e os RN são mais manipulados e expostos a procedimentos dolorosos. Assim, o contato pele a pele passa a ser benéfico tanto para a criança como para os pais.

Conclui-se que, a efetiva implementação do MC nas maternidades brasileiras, só ocorrerá a partir de mudanças no olhar e na postura de gestores e profissionais de saúde, e com a entrada dos pais nas unidades neonatais e a sua participação, de fato, no cuidado do filho pré-termo.

\section{Referências}

Aires, L. C. P., Koch, C., Santos, E. K. A., Costa, R., Mendes, J. S., \& Medeiros, G. M. S. (2020). Método canguru: estudo documental de teses e dissertações da enfermagem brasileira (2000-2017). Revista Brasileira de Enfermagem, 73(2), e20180598. https://www.scielo.br/pdf/reben/v73n2/pt_0034-7167-reben-7302-e20180598.pdf

Alves, F. N., Azevedo, V. M. G. O., Moura, M. R. S., Ferreira, D. M. L. M., Araújo, C. G. A., Mendes-Rodrigues, C., \& Wolkers, P. C. B. (2020). Impacto do método canguru sobre o aleitamento materno de recém-nascidos pré-termo no Brasil: uma revisão integrativa. Ciência \& Saúde Coletiva, 25(11), 4509-4520.https://doi.org/10.1590/1413-812320202511.29942018

Basso, C. S. D., Arroyo, M. A. S., Branco, M. A., Beani, L., Maia, A. B., \& Lourenção, L. G. (2019). Índice de aleitamento materno e atuação fonoaudiológica no método canguru. Revista Cefac, 21(5), e11719.- https://doi.org/10.1590/1982-0216/201921511719

Brito, A. C. M., Ferreira, A. F. C., Sobrinho, C. R. O., Rocha, D. S. A., Oliveira, D. F. C., Costa, L. A. Martins, R. S., \& Parente, J. S. (2020). A importância da enfermagem para uma execução efetiva do método canguru. Research, Society and Development, 9(12), e30091211102. http://dx.doi.org/10.33448/rsdv9i12.11102

Correia, A., \& Lourenço, M. (2020). Promoção do sono em unidades de cuidados intensivos neonatais: Scoping review. Enfermeria Global. 19(1), 527-575. http://dx.doi.org/10.6018/eglobal.19.1.370941

Costa, R., Azevedo, V. M. G. O., Sanches, M. T. C., Bueno, A. C., \& Machado, L. G. (2015). Contribuições de autores nacionais para a produção de conhecimento sobre o método canguru. In Sanches, M. T. C. R., Costa, V. M. G. O., Azevedo, D. S., \& Lamy,Morsch, Z. C. Método canguru no Brasil: 15 anos de política pública (pp. 211-244). Instituto de Saúde.

Dantas, J. M., Leite, H. C., Querido, D. L., Esteves, A. P. V. S., Almeida, V. S., Melo, M. M., Haase, C., \& Labolita, T. H. (2018). Percepção das mães sobre a aplicabilidade do método canguru. Revista de Enfermagem UFPE on line, 12(11), 2944-2951. https://periodicos.ufpe.br/revistas/revistaenfermagem/article/view/235196

Diniz, K. T., Filho, J. E. C., Miranda, R. M., Lima, G. M. S., Figueredo, N. P. S., \& Araújo, K. F. N. (2020). Short-time effect of the kangaroo position on electromyographic activity of premature infants: a randomized clinical trial. Jornal Pediatria, 96(6), 741-747. https://doi.org/10.1016/j.jped.2019.10.003

Farias, S. R., Dias, F. S. B., Silva, J. B., Cellere, A. L. L. R., Beraldo, L., \& Carmona, E. V. (2017). Posição canguru em recém-nascidos pré-termo de muito baixo peso: estudo descritivo. Revista Eletrônica de Enfermagem, 19(14), 1-11. https://doi.org/10.5216/ree.v19.38433

Ferreira, D. O., Silva, M. P. C., Galon, T., Goulart, B. F., Amaral, J. B., \& Contim, D. (2019). Método canguru: Percepções sobre o conhecimento, potencialidades e barreiras entre enfermeiras. Escola Anna Nery, 23(4), e20190100.- http://dx.doi.org/10.1590/2177-9465-ean-2019-0100

Ferreira, M. B., Monteiro, D. R., \& Souza, T. C. (2020). Em busca da humanização na UTI neonatal: método mãe canguru. Research, Society and Development, 9 (11), e3089119631.- http://dx.doi.org/10.33448/rsd-v9i11.9631

Gomes, R. Análise e interpretação de dados de pesquisa qualitativa. In: Minayo M. C. S., Deslandes S. F., \& Gomes R. (2016). Pesquisa social: Teoria, método e criatividade. Série Manuais Acadêmicos. (34a ed.). Vozes.

Heck, G. M. M., Lucca, H. C., Costa, R., Junges, C. F., Santos, S. V., \& Borck, M. (2016). Compreensão do sentimento materno na vivência no método canguru. Revista de Enfermagem da UFSM, 6(1), 71-83. https://periodicos.ufsm.br/reufsm/article/view/18083/13141

Lim, J. H., Shin, J. E., Lee, S. M., Eun, H. S., Park, M. S., Park, K. I., \& Namgung, R. (2015). Efficacy and safety of kangaroo mother care in preterm infants in korea. Korean Journal Perinatology. 26(4), 305-311. http://doi.org/10.14734/kjp.2015.26.4.305

Lopes, T. R.G., Santos, V. E. P., \& Carvalho, J. B. L. (2019). A presença do pai no método canguru. Escola Anna Nery, 23(3), e20180370. https://www.scielo.br/pdf/ean/v23n3/pt_1414-8145-ean-23-03-e20180370.pdf

Melo, A. M., Martins, T. G. S., Santos, T. L., Silva, A. S., \& Santos, N. N. S. (2016). Perfil alimentar e desenvolvimento motor oral dos neonatos nascidos com baixo peso. Revista Cefac, 18(1), 86-94. https://doi.org/10.1590/1982-021620161814415

Ministério da Saúde. (2017). Atenção humanizada ao recém-nascido: Método Canguru (3ª ed.). Secretaria de Atenção à Saúde, Departamento de Ações Programáticas Estratégicas. https://bvsms.saude.gov.br/bvs/publicacoes/atencao_humanizada_metodo_canguru_manual_3ed.pdf 
Research, Society and Development, v. 10, n. 2, e3310212102, 2021

(CC BY 4.0) | ISSN 2525-3409 | DOI: http://dx.doi.org/10.33448/rsd-v10i2.12102

Nietsche, E. A., Papa, M. M., Terra, L. G., Reisdorfer, A. P., Ramos, T. K., \& Antunes, A. P. (2020). Método Canguru: estratégias de Educação Permanente para sua implementação e execução. Rev Cuidarte, 11(1), e897. https://doi.org/10.15649/cuidarte.897

Oliveira, L. L., Gonçalves, A. C., Costa, S. J. D., \& Bonilha, A. L. L. (2016). Fatores maternos e neonatais relacionados à prematuridade. Revista da Escola de Enfermagem da USP, 50(3), 382-389. https://doi.org/10.1590/S0080-623420160000400002

Pascal, A., Govaert, P., Oostra, A., Naulaers, G., Ortibus, E., \& Broeck. C. V. D. (2018). Neurodevelopmental outcome in very preterm and very-lowbirthweight infants born over the past decade: a meta-analytic review. Developmental Medicine \& Child Neurology. 60, 342355.https://doi.org/10.1111/dmcn.13675

Rover, M. M. S., Vieira, C. S., Silveira, R. C., Guimarães, A. T. B., \& Grassiolli, S. (2016). Risk factors associated with growth failure in the follow-up of very low birth weight newborns. Jornal de Pediatria. 92(3), 307-313.- http://dx.doi.org/10.1016/j.jped.2015.09.006

Sales, I. M. M., Santos, J. D. M., Rocha, S. S. D., Gouveia, M. T. O., \& Carvalho, N. A. R. (2018). Contribuições da equipe enfermagem na segunda etapa do método canguru: implicações para a alta hospitalar do recém-nascido. Escola Anna Nery. 22(4), e20180149. https://doi.org/10.1590/2177-9465-ean-2018-0149

Souza, A. K. C. M., Tavares, A. C. M., Carvalho, D. G. L., \& Araújo, V.C. (2018). Ganho de peso em recém-nascidos submetidos ao contato pele a pele. Revista Cefac, 20(1), 53-60. https://www.scielo.br/pdf/rcefac/v20n1/pt_1982-0216-rcefac-20-01-00053.pdf

Souza, S. C., Medino, Y. M. S., Benevides, K. G. C. B., Ibiapina, A. S., \& Ataíde, K. M. N. (2019). Fortalecimento do vínculo entre a família e o neonato prematuro. Revista de Enfermagem UFPE on line, 13(2), 298-306. https://periodicos.ufpe.br/revistas/revistaenfermagem/article/view/236820/31268

Yin, R. K. (2015). Estudo de Caso: Planejamento e métodos. (5a ed.). Bookman.

Zirpoli, D. B., Mendes, R. B., Barreiro, M. S. C., Reis, T. S., \& Menezes, A. F. (2019). Benefícios do método canguru: uma revisão integrativa. Revista online de Pesquisa Cuidado é Fundamental, 11 (n.esp.), 547-554. http://www.seer.unirio.br/index.php/cuidadofundamental/article/view/6541/pdf 